\title{
The Steroid Content of Adrenal Adenomas and Measure- ments of Aldosterone Production in Patients with Essential Hypertension and Primary Aldosteronism *
}

\author{
Norman M. Kaplan † With the tech nical assistance of Robert Cook \\ and Stevon ne Gulley
}

(From the Department of Internal Medicine, The University of Texas Southwestern Medical School, Dallas, Texas)

\begin{abstract}
Summary. The content of aldosterone, corticosterone, and cortisol has been assayed in normal adrenal tissue obtained at autopsy and in adrenal adenomas from both normotensive and hypertensive patients obtained at autopsy and from patients with primary aldosteronism obtained at surgery. The content of aldosterone and corticosterone in the adenomas of patients with essential hypertension was similar to that of normal adrenal tissue and much less than that of adenomas from patients with primary aldosteronism.

Since these results do not appear to reflect various extraneous factors such as assay technique, degradation of steroids, and patient selection, they suggest that most adrenal adenomas found in patients with essential hypertension are not associated with increased aldosterone production. The presence of such adenomas should not, in itself, be considered evidence for primary aldosteronism.

The excretion or secretion of aldosterone in 43 hypertensive patients was found to be similar to that of 39 normotensive patients. These results suggest that primary aldosteronism is rarely the cause of "essential" hypertension.
\end{abstract}

\section{Introduction}

Benign adrenocortical adenomas have long been recognized as occurring more frequently in patients with hypertension than in normotensive subjects (1). These adenomas have generally

* Submitted for publication August 5, 1966; accepted January 4, 1967.

Presented in part at the 38th Annual Meeting of the Central Society for Clinical Research, November 5, 1965, and the endocrinology sectional meeting of the American Society for Clinical Investigation and the American Federation for Clinical Research, May 1, 1966.

Supported by grants from the Dallas Heart Association and the U. S. Public Health Service, National In-a stitute of Arthritis and Metabolic Diseases (AM 0693804) and General Medical Sciences (NIH 5T01 GM 1421 01).

$\dagger$ Address requests for reprints to Dr. Norman M. Kaplan, Dept. of Internal Medicine, The University of Texas Southwestern Medical School, 5323 Harry Hines Blvd., Dallas, Texas 75235. been considered to be "incidental" and of no functional significance (2), since none of the expected clinical features of adrenal hormone excess were usually observed in patients found to have them at autopsy.

However, the possibility that such adenomas may be causally related to the hypertensive process has been proposed (3). The reports by Conn and his associates have strongly suggested that such adenomas producing excess amounts of aldosterone may be the cause of as much as $20 \%$ of all essential hypertension (4).

In view of this suggestion, we have attempted to determine the functional significance of adrenal adenomas in patients with essential hypertension by comparing the steroid content of such adenomas with that of normal adrenal tissue and adenomas removed from patients with primary aldosteronism. The results suggest that most adrenal adenomas found in patients with essential hypertension prob- 
ably are not producing excess amounts of aldosterone.

We sought additional evidence concerning the incidence of primary aldosteronism by measuring either urinary aldosterone excretion or the aldosterone secretory rate in patients with essential hypertension. No significant difference in aldosterone production between such patients and normotensive subjects was found.

\section{Methods}

Source of adrenal tissue. Adrenocortical adenomas are here defined as solitary nodules greater than $5 \mathrm{~mm}$ in diameter composed of cords of lipoid-engorged cells without identifiable zonation, which are demarcated by a partial capsule or compression of adjacent adrenal tissue.

Adenomas were removed surgically from seven patients with the classical clinical and laboratory features of primary aldosteronism, including hypokalemia and elevated urinary aldosterone excretion. These features disappeared after unilateral adrenalectomy.

All other adrenal glands were obtained at autopsy. The "normal" glands were obtained from seven patients who died of the following causes: acute myocardial infarction (two), sudden trauma (two), chronic renal insufficiency (one), pulmonary embolus (one), and carcinoma of the stomach (one). Three of these patients had been hypertensive. Two glands with solitary adenomas were found in patients who had been normotensive, and 11 were found in patients whose blood pressures had been above $140 / 90 \mathrm{~mm} \mathrm{Hg}$ and whose heart weights were above $500 \mathrm{~g}$ for men or $450 \mathrm{~g}$ for women. These patients had had normal serum potassium concentrations when measured at least twice during the year before death, and did not have hemorrhages, exudates, or papilledema in the optic fundi; there were no specific causes for hypertension found post-mortem. The living patients studied met similar criteria, except that specific causes for hypertension were excluded by the usual clinical techniques, including intravenous pyelography.

Patient selection. Assays of aldosterone excretion or secretion were performed on 39 normotensive and 43 hypertensive patients. They had been hospitalized for various medical problems, but all were ambulatory, eating a regular diet, off medication, and free of overt manifestations of disease when studied. All such patients available during a 6-month interval were studied. During this interval, none of the seven patients with primary aldosteronism were diagnosed.

We considered the hypertensive patients to have essential hypertension by excluding specific causes of hypertension by physical examination, intravenous pyelography, urinary 17-hydroxycorticoid and catecholamine assays, and, in 16 patients, renal arteriography. Patients were excluded who had hemorrhages, exudates or papilledema in the optic fundi, renal disease with azotemia, or heart failure.
Serum potassium had been below $3.5 \mathrm{mEq}$ per $\mathrm{L}$ in five of the normotensive and seven of the hypertensive patients when they were admitted to the hospital. An extrarenal cause of potassium loss was known for all twelve patients and was demonstrated by the finding of less than $30 \mathrm{mEq}$ of potassium in a 24-hour urine collection. Supplemental potassium had been given to ten of these patients but had been discontinued for at least 1 week before study of aldosterone production. At that time, the serum potassium was between 3.8 and $5.0 \mathrm{mEq}$ per $\cdot \mathrm{L}$ in all patients, and all were on regular hospital diets with unrestricted access to salt. The adequacy of sodium intake was determined by the presence of more than 100 $\mathrm{mEq}$ of sodium in the 24-hour urine collection.

Steroid measurements. Urinary aldosterone excretion was measured by the technique of Kliman and Peterson (5). Aldosterone secretion was measured by an isotopic dilution technique, in which $1 \mu \mathrm{c}$ of tritium-labeled aldosterone diluted in $20 \mathrm{ml}$ of $5 \%$ ethanol was injected intravenously at the start of the urine collection. The aldosterone released by incubation at $\mathrm{pH} 1$ for 24 hours was identified by chromatography in the Bush C system, eluted, acetylated with acetic anhydride- ${ }^{14} \mathrm{C}$ of known specific activity, and thereafter purified in the same manner as in the urinary excretion measurements. Using standard isotopic dilution equations, we determined the 24-hour secretion rate from the ${ }^{8} \mathrm{H}$ to ${ }^{14} \mathrm{C}$ ratio of the purified sample.

Assay of adrenal tissue. The adrenal tissue was kept frozen until assayed by a modification of the double isotopic derivative assay of Kliman and Peterson (5). Only cortical tissue from the normal glands was used. From 200 to $800 \mathrm{mg}$ of tissue was placed in $5 \mathrm{ml}$ water, and 2,000 cpm of ${ }^{14} \mathrm{C}$-labeled aldosterone, corticosterone, and cortisol was added. The tissue was homogenized, and the steroids were extracted with methylene dichloride. The extract was washed with $0.05 \mathrm{~N} \mathrm{NaOH}, 0.1 \mathrm{~N}$ acetic acid, and petroleum ether. The methylene dichloride was evaporated and the steroid residue kept in a dessicator for 24 hours.

The extract was streaked onto chromatography paper with appropriate nonradioactive steroid markers on either side and run for 4 hours in the Bush C system (toluene 450 , methanol 250 , water 250 , ethyl acetate $50 \mathrm{vol} / \mathrm{vol}$ ). The appropriate areas were eluted together in ethanol, and the extract was dried and acetylated with acetic anhydride- ${ }^{-3} \mathrm{H}, 25 \mathrm{mc}$ per mmole. After the addition of the three nonradioactive steroid acetates as markers, the samples were chromatographed in a cyclohexane: dioxane: methanol: water $(100: 75: 50: 25 \mathrm{vol} / \mathrm{vol})$ system for 15 hours, which provided separation of aldosterone diacetate, corticosterone acetate, and cortisol acetate. The separate areas of each steroid were then individually chromatographed, first in the cyclohexane: benzene: methanol: water $(100: 33: 100: 25 \mathrm{vol} / \mathrm{vol})$ system and then after oxidation with chromium trioxide, in the cyclohexane : benzene : methanol: water $\quad(100: 75: 100: 25$ $\mathrm{vol} / \mathrm{vol}$ ) system. The appropriate areas were eluted and counted for ${ }^{8} \mathrm{H}$ and ${ }^{14} \mathrm{C}$ in a liquid scintillation spectrom- 
eter. All values were expressed as micrograms steroid per gram tissue.

Stability of steroids in adrenal tissue. Since comparisons were to be made from adrenal tissue frozen within an hour after surgical removal from living patients with primary aldosteronism and after removal at autopsy from cadavers kept at $2^{\circ} \mathrm{C}$ for 6 to 18 hours, the effects of time and temperature on steroid content were first studied.

Adrenal glands from four cattle were obtained within 15 minutes after death, and portions were frozen immediately or kept at 25 or $37^{\circ} \mathrm{C}$ for 6 to 24 hours and then frozen. A similar procedure was followed for one adrenal adenoma surgically removed from a patient with primary aldosteronism. Steroid content was assayed in the manner previously described. As seen in Table $\mathrm{I}$, only in those tissues kept at $37^{\circ}$ for 24 hours was a marked decrease in aldosterone and corticosterone content noted. In the adenoma kept at $37^{\circ}$ for 24 hours, the level of aldosterone fell by $22 \%$, the level of corticosterone $45 \%$, of that in the tissue frozen immediately. The cortisol content fell sharply within 6 hours at $37^{\circ}$ and 24 hours at $25^{\circ} \mathrm{C}$ in the cattle glands, but only after 24 hours at both temperatures in the adenoma.

The rate of cooling in the inner core of the human cadaver in refrigerated vaults is variable, depending on the cause of death, amount of body fat, and so forth. However, it can be assumed that the adrenal glands were near $37^{\circ} \mathrm{C}$ for only a few hours and probably below $25^{\circ} \mathrm{C}$ for most of the time between death of the patient and removal of the tissue. Therefore, any observed differences between the "fresh" and postmortem tissues are probably not caused simply by loss of steroid from the glands obtained at autopsy.

\section{Results}

Steroid content. The results of the assays on the nonadenomatous adrenal tissue from the seven normal patients and the solitary adenomas removed at surgery from seven patients with primary aldos-

TABLE I

Effects of time and temperature on steroid content of adrenal tissue

\begin{tabular}{lccccr}
\hline \hline $\begin{array}{c}\text { Source of } \\
\text { tissue }\end{array}$ & $\begin{array}{c}\text { Time } \\
\text { after } \\
\text { death }\end{array}$ & $\begin{array}{c}\text { Tem- } \\
\text { perature }\end{array}$ & $\begin{array}{c}\text { Aldos- } \\
\text { terone }\end{array}$ & $\begin{array}{c}\text { Corti- } \\
\text { costerone }\end{array}$ & Cortisol \\
\hline & hours & ${ }^{\circ} C$ & & $\begin{array}{c}\mu g / g \\
\text { tissue }\end{array}$ & \\
Cattle & & & & 5.63 & 10.33 \\
& 6 & & 0.64 & 5.57 & 8.28 \\
& 6 & 25 & 0.53 & 5.01 & 2.76 \\
& 24 & 25 & 0.43 & 3.08 & 2.71 \\
& 6 & 37 & 0.46 & 3.15 & 1.53 \\
Adenoma & 24 & 37 & 0.13 & 2.15 & \\
from patient & 0 & & 5.03 & 15.41 & 24.65 \\
& 6 & 25 & 5.21 & 17.50 & 22.96 \\
& 24 & 25 & 4.65 & 11.67 & 14.43 \\
& 6 & 37 & 4.88 & 12.33 & 20.02 \\
& 24 & 37 & 3.96 & 8.40 & 4.53 \\
& & & & & \\
\hline
\end{tabular}

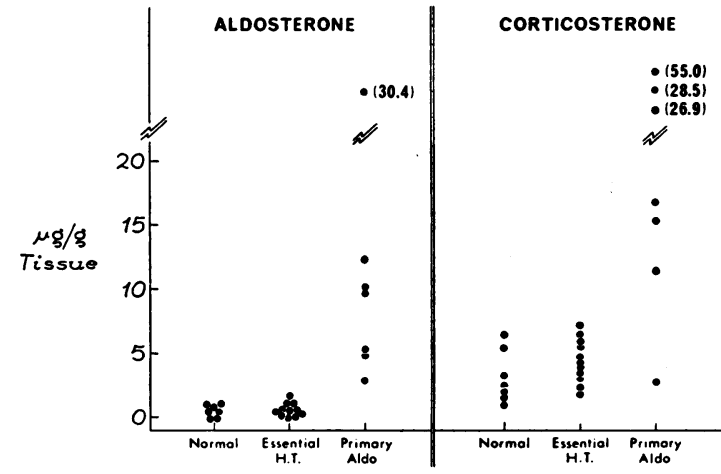

Fig. 1. Content of aldosterone AND CORTICOSTERone IN NORMAL ADRENAL TISSUE, CORTICAL ADENOMAS FROM PATIENTS WITH ESSENTIAL HYPERTENSION, AND ADENOMAS FROM PATIENTS WITH PRIMARY ALDOSTERONISM.

teronism and at autopsy from two previously normotensive and eleven previously hypertensive patients are shown in Table II. The individual values for aldosterone and corticosterone are shown in Figure 1.

Compared with the normal glands, the content of aldosterone and corticosterone was markedly increased in the adenomas of patients with primary aldosteronism. However, the adenomas found in the normotensive patients and those with essential hypertension contained amounts of aldosterone and corticosterone similar to those in normal tissue. Adrenal tissue adjacent to the adenomas of three of the patients with essential hypertension was also analyzed. The content of aldosterone and corticosterone was slightly lower in the nonadenomatous tissues than in the adenomas, with mean values of 0.29 and $3.86 \mu \mathrm{g}$.per $\mathrm{g}$ tissue, respectively. The content of cortisol was similar in all four types of adrenal tissue. Since the level of cortisol was most markedly altered in adrenal tissue left for 6 to 24 hours at 25 or $37^{\circ}$, the finding of similar cortisol contents in the fresh and postmortem tissues should be strong evidence that the observed changes in aldosterone content were not simply the result of degradation in the postmortem tissue.

These levels of steroid content of both normal adrenal tissue and adenomas of patients with primary aldosteronism are higher than most of those previously reported (6-8). However, these results were obtained with a more sensitive technique than that used in the first two studies (6, 
TABLE II

Steroid content of adrenal tissue

\begin{tabular}{|c|c|c|c|c|c|c|c|c|}
\hline Patient & Age & Sex & $\begin{array}{c}\text { Blood } \\
\text { pressure }\end{array}$ & $\begin{array}{l}\text { Serum } \\
\mathrm{Na} / \mathrm{K}\end{array}$ & $\begin{array}{l}\text { Tissue } \\
\text { weight }\end{array}$ & Aldosterone & Corticosterone & Cortisol \\
\hline \multicolumn{9}{|c|}{ "Normal" adrenal glands } \\
\hline $\begin{array}{l}\text { L.V. } \\
\text { W.B. } \\
\text { R.T. } \\
\text { C.W. } \\
\text { R.W. } \\
\text { A.C. } \\
\text { P.L. }\end{array}$ & $\begin{array}{l}71 \\
27 \\
34 \\
85 \\
79 \\
45 \\
50\end{array}$ & $\begin{array}{l}M \\
M \\
M \\
F \\
F \\
F \\
F\end{array}$ & $\begin{array}{l}130 / 80 \\
180 / 110 \\
160 / 95 \\
175 / 100 \\
120 / 75 \\
120 / 80 \\
130 / 85\end{array}$ & $\begin{array}{l}142 / 4.6 \\
138 / 4.0 \\
140 / 3.8 \\
136 / 3.5 \\
141 / 4.3 \\
140 / 4.5 \\
138 / 4.2\end{array}$ & $\begin{array}{l}3.5 \\
4.1 \\
3.2 \\
3.0 \\
4.8 \\
3.8 \\
4.1\end{array}$ & $\begin{array}{l}0.26 \\
0.33 \\
0.25 \\
0.18 \\
0.62 \\
0.11 \\
0.15\end{array}$ & $\begin{array}{l}6.52 \\
3.03 \\
2.08 \\
4.65 \\
0.82 \\
2.00 \\
2.88\end{array}$ & $\begin{array}{r}9.92 \\
5.46 \\
12.28 \\
17.38 \\
5.75 \\
6.66 \\
13.60\end{array}$ \\
\hline Mean & & & & & & 0.27 & 3.14 & 10.15 \\
\hline \multicolumn{9}{|c|}{ Adenomas from patients with primary aldosteronism } \\
\hline $\begin{array}{l}\text { W.E. } \\
\text { L.W. } \\
\text { M.J. } \\
\text { D.D. } \\
\text { M.B. } \\
\text { J.T. } \\
\text { M.S. }\end{array}$ & $\begin{array}{l}42 \\
48 \\
34 \\
55 \\
48 \\
52 \\
43\end{array}$ & $\begin{array}{l}M \\
M \\
F \\
M \\
F \\
M \\
M\end{array}$ & $\begin{array}{l}210 / 140 \\
180 / 120 \\
180 / 95 \\
180 / 110 \\
200 / 110 \\
180 / 115 \\
170 / 100\end{array}$ & $\begin{array}{r}145 / 2.6 \\
142 / 3.0 \\
137 / 2.2 \\
148 / 2.5 \\
145 / 3.2 \\
144 / 2.9 \\
142 / 2.6\end{array}$ & $\begin{array}{l}4.8 \\
0.7 \\
2.1 \\
1.6 \\
1.5 \\
1.2 \\
0.5\end{array}$ & $\begin{array}{r}9.44 \\
30.40 \\
4.08 \\
11.71 \\
4.53 \\
9.52 \\
2.70\end{array}$ & $\begin{array}{r}2.30 \\
11.25 \\
55.02 \\
26.88 \\
14.41 \\
28.47 \\
15.81\end{array}$ & $\begin{array}{r}2.39 \\
11.52 \\
8.11 \\
15.03 \\
24.65 \\
10.43 \\
4.48\end{array}$ \\
\hline Mean & & & & & & 10.34 & 22.02 & 10.94 \\
\hline \multicolumn{9}{|c|}{ Adenomas from normotensive patients } \\
\hline $\begin{array}{l}\text { W.F. } \\
\text { M.Y. }\end{array}$ & $\begin{array}{l}63 \\
56\end{array}$ & $\begin{array}{l}\mathrm{M} \\
\mathrm{F}\end{array}$ & $\begin{array}{l}120 / 80 \\
130 / 85\end{array}$ & $\begin{array}{l}140 / 3.6 \\
139 / 4.3\end{array}$ & $\begin{array}{l}1.6 \\
1.2\end{array}$ & $\begin{array}{l}0.31 \\
0.18\end{array}$ & $\begin{array}{l}4.44 \\
3.69\end{array}$ & $\begin{array}{l}6.23 \\
5.13\end{array}$ \\
\hline Mean & & & & & & 0.24 & 4.06 & 5.68 \\
\hline \multicolumn{9}{|c|}{ Adenomas from patients with essential hypertension } \\
\hline $\begin{array}{l}\text { B.M. } \\
\text { A.S. } \\
\text { E.R. } \\
\text { B.Y. } \\
\text { I.H. } \\
\text { L.J. } \\
\text { M.O. } \\
\text { L.S. } \\
\text { C.C. } \\
\text { A.S. } \\
\text { P.Q. }\end{array}$ & $\begin{array}{l}79 \\
48 \\
66 \\
56 \\
50 \\
55 \\
86 \\
76 \\
33 \\
56 \\
65\end{array}$ & $\begin{array}{l}F \\
M \\
F \\
F \\
M \\
F \\
M \\
F \\
F \\
F \\
M\end{array}$ & $\begin{array}{l}200 / 120 \\
190 / 120 \\
180 / 100 \\
145 / 95 \\
160 / 95 \\
170 / 105 \\
210 / 130 \\
160 / 100 \\
175 / 105 \\
150 / 100 \\
190 / 110\end{array}$ & $\begin{array}{l}136 / 4.1 \\
140 / 4.7 \\
135 / 3.6 \\
138 / 4.0 \\
136 / 3.6 \\
140 / 4.1 \\
142 / 4.0 \\
136 / 4.8 \\
140 / 4.5 \\
138 / 4.1 \\
140 / 3.7\end{array}$ & $\begin{array}{l}2.3 \\
0.8 \\
0.9 \\
1.3 \\
1.0 \\
1.1 \\
0.6 \\
0.5 \\
2.8 \\
1.8 \\
1.1\end{array}$ & $\begin{array}{l}0.36 \\
0.30 \\
0.52 \\
0.23 \\
0.11 \\
0.75 \\
0.23 \\
0.29 \\
0.68 \\
0.24 \\
0.35\end{array}$ & $\begin{array}{l}7.36 \\
4.08 \\
3.44 \\
2.23 \\
4.34 \\
6.08 \\
6.02 \\
1.68 \\
4.41 \\
3.02 \\
6.21\end{array}$ & $\begin{array}{r}8.78 \\
10.06 \\
9.03 \\
8.15 \\
7.77 \\
11.40 \\
3.56 \\
12.22 \\
6.03 \\
8.47 \\
6.51\end{array}$ \\
\hline Mean & & & & & & 0.37 & 4.44 & 8.36 \\
\hline
\end{tabular}

7). No normal tissue was measured by Biglieri, Hane, Slaton, and Forsham, so comparisons cannot be made (8).

Measurements of aldosterone production. The 24-hour urinary aldosterone excretion or aldosterone secretion rates of 39 normotensive and 43 hypertensive patients are shown in Figure 2 . Although the mean values for the patients with essential hypertension are slightly higher (10.9 and 112 compared to 10.1 and 90 ), the differences are not statistically significant $(p>0.2)$. Moreover, the distributions of the values within the two groups appear similar.

Aldosterone secretion was above $150 \mu \mathrm{g}$ per day in one normotensive and two hypertensive patients, and aldosterone excretion was above 15 $\mu \mathrm{g}$ per day in four normotensive and six hypertensive patients. In an attempt to demonstrate that these higher values were normal, plasma renin activity was measured in six of these thirteen patients, one normotensive and five hypertensive. The blood was obtained first while they were on a regular diet and supine, and then after 3 days on a $500-\mathrm{mg}$ low salt diet and 4 hours upright. The assays were performed by a modification of the Helmer technique. ${ }^{1}$ All six pa1 Performed in the laboratory of Dr. J. Caulie Gunnels at Duke Medical Center. 


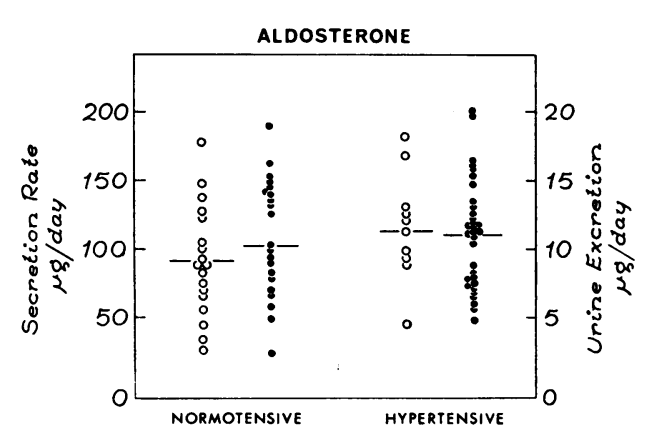

Fig. 2. Aldosterone secretion (OPEN dots) OR EXCRETION (CLOSED DOTS) IN 39 NORMOTENSIVE PATIENTS AND 43 With "ESSENTIAL" hypertension.

tients had a greater than threefold rise in plasma renin activity to a value above $300 \mathrm{ng}$ per $100 \mathrm{ml}$ plasma after a 1 -hour incubation. These values demonstrate a normal responsiveness of plasma renin activity and are further evidence that these patients with relatively high aldosterone assays are, in fact, normal.

\section{Discussion}

Autonomous hypersecretion of aldosterone from a benign adrenocortical adenoma was first reported in $1955(9,10)$. Since then, over 200 cases of primary aldosteronism have been reported, and all have been associated with hypertension (11). The hypertension seen with primary aldosteronism has been, with rare exceptions, of a benign type, indistinguishable from essential hypertension. The presence of hypokalemia has been the usual major diagnostic criterion for the recognition of this syndrome among patients with hypertension. However, Conn, Cohen, Rovner, and Nesbit have recently discovered aldosterone-secreting adenomas in normokalemic patients (12). They suggest that primary aldosteronism may be the cause of as much as $20 \%$ of all essential hypertension.

One of the reasons given for this view on the large incidence of primary aldosteronism is the finding of adrenocortical adenomas greater than $1.0 \mathrm{~cm}$ in diameter in as many as $20 \%$ of hypertensive subjects but in only $1.8 \%$ of normotensive subjects at autopsy (3). However, if smaller adenomas that measure between 0.5 and $1.0 \mathrm{~cm}$ are included, their incidence in this study in the hypertensive patients was $88 \%$ and in normotensive patients, $44 \%$ (3). These adenomas are indistinguishable grossly and microscopically from those seen in overt primary aldosteronism. Other authors have found only a twofold increased incidence of adenomas among hypertensive patients (13-15). In the two large series, the incidences of adenomas among hypertensive patients were only 5 and $7.4 \%(15,16)$. Nonetheless, all agree that such adenomas are found in many patients with hypertension, many more than have been thought to have primary aldosteronism. However, it is not yet known whether these adenomas are the cause of the hypertension or simply incidental findings of no functional significance.

The steroid analyses performed on adenomas from patients with essential hypertension suggest that they do not produce increased amounts of aldosterone and therefore are not the cause of primary aldosteronism. These adenomas contained no more aldosterone than normal adrenal tissue, and only about one-twentieth that found in adenomas removed from patients with primary aldosteronism.

Certain limitations on the use of these data as an indication of the role of adrenal adenomas in hypertension are obvious. First, the assay of steroid content is a static measurement, which may have little relationship to the secretory function of these adenomas during life. However, as also noted in this study, aldosterone excretion and secretion from patients with essential hypertension have been normal in all series that had careful selection of patients and reliable assay procedures (17-21). Secondly, the adenomas from patients with essential hypertension were obtained after death, when considerable degradation of steroids may have occurred. However, the possibility that such postmortem degradation could explain these differences appears unlikely, since such degradation was not found in adrenal tissue subjected to similar conditions. Moreover, any differences between the adenomas from patients with essential hypertension and normal tissue should have persisted even though the total content decreased, since they were obtained and handled in the same manner. Thirdly, the patients with essential hypertension and adrenal adenomas may have had aldosterone excess during life, since neither urinary aldosterone nor plasma renin activity was measured. Conn suggests that the serum potassium in primary aldos- 
teronism may remain normal for many years, and, so, the essential hypertensive patients in this study may have been in the normokalemic phase of the disease. This appears unlikely since, despite the presence of significant hypertension for from 6 to 24 years, none of the patients had abnormal serum sodium or potassium levels.

The adrenocortical adenomas found at autopsy, more commonly in hypertensive but also in normotensive patients, do not then appear to be associated with aldosterone excess. They could be the cause of hypertension by producing other steroids not measured in this study, such as deoxycorticosterone.

The pathogenesis of these adenomas is unknown. Adenomas in other endocrine tissues are frequently found at autopsy without evidence of hyperfunction during life. The possibility that these adenomas are secondary to the hypertensive process should be considered, particularly since autonomous adenomas of the thyroid and parathyroid glands have been noted after prolonged "secondary" stimulation. A form of secondary aldosteronism does appear with malignant hypertension, presumably from stimulation of the adrenal cortex by increased amounts of renin released from the juxtaglomerular apparatus in response to the ischemia produced by intrarenal vascular disease $(17,22)$. However, this secondary stimulation produces a diffuse nodular hyperplasia, not a solitary adenoma, and the hypertensive process is of a malignant nature, not the long-standing benign hypertension almost always seen with primary aldosteronism. Conn, Cohen, and Rovner could find no evidence to support the view that autonomous adrenal adenomas arise from prolonged secondary stimulation (23). The issue is confused by the production of typical primary aldosteronism with benign hypertension by diffuse adrenocortical hyperplasia (24), but this has been a relatively rare finding (11) and there is no reason to believe that such diffuse hyperplasia would later give rise to a solitary adenoma. It appears, then, that such adrenal adenomas in hypertensive patients are not secondary to the hypertensive process itself, particularly since adenomas of similar appearance and steroid content occur frequently in normotensive subjects.
It may be that these incidental adenomas commonly appear and, in most patients, simply suppress the function of the remainder of the gland but leave the patient in a normal state. Such a mechanism has been suggested in a report of a normotensive normokalemic subject found to have a solitary adrenocortical adenoma and atrophy of the zona glomerulosa (25). Such marked atrophy of the rest of the adrenal tissue was not observed in the glands we studied.

Another piece of evidence used in support of the 20 to $25 \%$ incidence of primary aldosteronism in essential hypertension (12) is the report that aldosterone excretion was elevated in $25 \%$ of 38 hypertensive patients (26). In that study as well as three other reports of aldosterone excess in hypertension (27-29), the aldosterone measurements were performed by a less specific and sensitive physicochemical technique, and the selection of patients was not delineated to ensure the exclusion of advanced or malignant hypertension, where aldosterone excess is expected. On the other hand, when isotopic techniques are used and patient selection is careful, the incidence of aldosterone excess in essential hypertension has been found to be one in 114 patients (17-21). Our data show no increase in the excretion or secretion of aldosterone in 43 essential hypertensive patients and no difference in their mean values when compared with 39 normotensive patients. There are other findings which suggest that aldosterone excess is not a frequent cause of essential hypertension. These include the following: normal plasma volume, serum sodium, and total body exchangeable sodium (30), all usually elevated in primary aldosteronism (11, 31 ) ; and normal plasma renin activity (21), suppressed in primary aldosteronism (4). Furthermore, whereas primary aldosteronism has been noted to be almost as common below the age of 40 as beyond that age (11), the occurrence of incidental adrenal adenomas is rare below 40 but increases progressively thereafter $(15,16)$. For these reasons it appears that primary aldosteronism is only rarely the cause of essential hypertension, and the finding of an adrenal adenoma should not be used as evidence for the presence of primary aldosteronism in the absence of supporting clinical or laboratory data. 


\section{Acknowledgment}

The assistance of Dr. J. Caulie Gunnels in the performance of the assays of plasma renin activity is gratefully acknowledged.

\section{References}

1. Oppenheimer, B. S., and A. M. Fishberg. The association of hypertension with suprarenal tumors. Arch. intern. Med. 1924, 34, 631.

2. Robbins, S. L. Textbook of Pathology, 2nd ed. Philadelphia, W. B. Saunders, 1962, p. 991.

3. Shamma, A. H., J. W. Goddard, and S. C. Sommers. A study of the adrenal status in hypertension. J. chron. Dis. 1958, 8, 587.

4. Conn, J. W. Plasma renin activity in primary aldosteronism. Importance in differential diagnosis and in research of essential hypertension. J. Amer. med. Ass. 1964, 190, 222.

5. Kliman, B., and R. E. Peterson. Double isotope derivative assay of aldosterone in biological extracts. J. biol. Chem. 1960, 235, 1639.

6. Neher, R. Aldosterone and other adrenocortical hormones in human adrenals and adrenal tumours in Aldosterone-An International Symposium, A. F. Muller and C. M. O'Connor, Eds. Boston, Little, Brown, 1958, p. 11.

7. Louis, L. H., and J. W. Conn. Primary aldosteronism: content of adrenocortical steroids in adrenal tissue. Recent Progr. Hormone Res. 1961, 17, 415.

8. Biglieri, E. G., S. Hane, P. E. Slaton, Jr., and P. H. Forsham. In vivo and in vitro studies of adrenal secretions in Cushing's syndrome and primary aldosteronism. J. clin. Invest. 1963, 42, 516.

9. Conn, J. W. Primary aldosteronism. II. A new clinical syndrome. J. Lab. clin. Med. 1955, 45, 6.

10. Mader, I. J., and L. T. Iseri. Spontaneous hypopotassemia, hypomagnesemia, alkalosis and tetany due to hypersecretion of corticosterone-like mineralocorticoid. Amer. J. Med. 1955, 19, 976.

11. Conn, J. W., R. F. Knopf, and R. M. Nesbit. Clinical characteristics of primary aldosteronism from an analysis of 145 cases. Amer. J. Surg. 1964, 107, 159.

12. Conn, J. W., E. L. Cohen, D. R. Rovner, and R. M. Nesbit. Normokalemic primary aldosteronism. A detectable cause of curable "essential" hypertension. J. Amer. med. Ass. 1965, 193, 200.

13. Dempsey, W. S. The adrenal cortex in essential hypertension. Arch. Path. 1942, 34, 1031.

14. Dawson, I. M. P. Changes in the adrenal cortex in essential and renal hypertension. J. Path. Bact. 1956, 72, 393.

15. Commons, R. R., and C. P. Callaway. Adenomas of the adrenal cortex. Arch. intern. Med. 1948, 81, 37.

16. Russi, S., H. T. Blumenthal, and S. H. Gray. Small adenomas of the adrenal cortex in hyperten- sion and diabetes. Arch. intern. Med. 1945, 76, 284.

17. Laragh, J. H., S. Ulick, V. Januszewicz, Q. B. Deming, W. G. Kelly, and S. Lieberman. Aldosterone secretion and primary and malignant hypertension. J. clin. Invest. 1960, 39, 1091.

18. Gerasimova, E. N. Aldosterone by hypertensive disease and symptomatic renal hypertension in A1dosterone, E. E. Baulieu and P. Robel, Eds. London, Blackwell, 1964, p. 449.

19. Yamauchi, H., E. G. Biglieri, and J. Hopper, Jr. Blood volume and aldosterone secretion in hypertension and primary aldosteronism. Proc. Soc. exp. Biol. (N. Y.) 1961, 107, 728.

20. Cope, C. L., M. Harwood, and J. Pearson. Aldosterone secretion in hypertensive diseases. Brit. Med. J. 1962, 1, 659.

21. Laragh, J. H., J. E. Sealey, and S. C. Sommers. Patterns of adrenal secretion and urinary excretion of aldosterone and plasma renin activity in normal and hypertensive subjects. Circulat. Res. 1966, 18 (suppl. 1), 158

22. Deane, H. W., and G. M. C. Masson. Adrenal cortical changes in rats with various types of experimental hypertension. J. clin. Endocr. 1951, 11, 193.

23. Conn, J. W., E. L. Cohen, and D. R. Rovner. Suppression of plasma renin activity in primary aldosteronism. Distinguishing primary from secondary aldosteronism in hypertensive disease. J. Amer. med. Ass. 1964, 190, 213.

24. Gilbert, J. W., N. H. Bell, and F. C. Bartter. Primary aldosteronism: diagnosis and surgical treatment. Ann. Surg. 1963, 158, 195.

25. Nichols, J. Unusual adrenal cortex. J. clin. Endocr. 1966, 26, 550.

26. Garst, J. B., N. P. Shumway, H. Schwartz, and G. L. Farrell. Aldosterone excretion in essential hypertension. J. clin. Endocr. 1960, 20, 1351.

27. Genest, J., E. Koiw, W. Nowaczynski, and T. Sandor. Study of a large steroid spectrum in normal subjects and hypertensive patients. Acta endocr. (Kbh.) 1960, 35, 413.

28. Venning, E. H., I. Dyrenfurth, J. B. Dossetor, and J. C. Beck. Essential hypertension and aldosterone. Circulation 1961, 23, 168.

29. Murakami, M., R. Takeda, S. Miyabo, S. Morimoto, K. Hasui, M. Kaneda, and T. Nagano. Urinary aldosterone and hypertension. Jap. Heart J. 1962, 3,5 .

30. Hollander, W., A. V. Chobanian, and B. A. Burrows. Body fluid and electrolyte composition in arterial hypertension. I. Studies in essential, renal and malignant hypertension. J. clin. Invest. 1961, 40, 408.

31. Slaton, P. E., and E. G. Biglieri. Hypertension and hyperaldosteronism of renal and adrenal origin. Amer. J. Med. 1965, 38, 324. 